Data Article

\title{
Enzymatic synthesis of geranyl acetate in packed bed reactor in supercritical carbon dioxide under various pressure-temperature conditions and reactor configurations
}

\author{
Mohamed Chafik Bourkaib, Harifeno Randriamalala, \\ Lena Dettori, Catherine Humeau, Stephane Delaunay, \\ Isabelle Chevalot, Yann Guiavarc'h*
}

Laboratory Reactions and Process Engineering, University of Lorraine, CNRS, LRGP, F-54000 Nancy, France

\section{A R T I C L E I N F O}

\section{Article history:}

Received 14 May 2018

Accepted 5 July 2018

Available online 20 July 2018

\begin{abstract}
A B S T R A C T
Data in this paper describes the catalytic performances, expressed in terms of conversion \%, of geraniol and acetic acid to geranyl acetate, using the immobilized lipase B from Candida antarctica in packed bed reactors (PBR) using supercritical $\mathrm{CO}_{2}$ as a solvent. Readers will find data related to different Figures or equations of the article as well as supplementary data that will help to make the difference between flowrates of $\mathrm{CO}_{2}$ in a liquid state and corresponding flowrates of supercritical $\mathrm{CO}_{2}$ for various $\mathrm{CO}_{2}$ pressure and temperature combinations.

(c) 2018 Published by Elsevier Inc. This is an open access article under the CC BY license (http://creativecommons.org/licenses/by/4.0/).
\end{abstract}

\section{Specifications Table}

Subject area

More specific subject area

Type of data
Process biochemistry

Green catalytic processing in supercritical $\mathrm{CO}_{2}$

Table, figure

\footnotetext{
DOI of original article: https://doi.org/10.1016/j.procbio.2018.05.008

* Corresponding author.

E-mail address: yann.guiavarch@univ-lorraine.fr (Y. Guiavarc'h).
} 
How data was acquired

Data format Experimental factors

Experimental features

Data source location Data accessibility Related research article
Immobilized enzyme water activity was checked to be 0.23 with a Novasina Lab-Master aw-meter.

Data on enzyme activity were acquired using an Agilent 7890A gas chromatograph equipped with a FID detector for quantification and coupled with an Agilent 7000A MS triple quad detector (Agilent technologies, Santa Clara, USA). An internal standard was used.

Raw, analyzed

$\mathrm{CO}_{2}$ pressure in the range 100-300 bar, $\mathrm{CO}_{2}$ temperature in the range $45-65{ }^{\circ} \mathrm{C}, \mathrm{CO}_{2}$ Flow rate in the range 0.5 to $6 \mathrm{~mL} / \mathrm{min}$, packed-bed reactor volume ( $1 \mathrm{~mL}, 2^{*} 1 \mathrm{~mL}$ in parallel, or $5 \mathrm{~mL}$ ), reaction time (0-22 hours), reaction cycles (6)

- study of the effect of pressure and temperature of supercritical $\mathrm{CO}_{2}$ on the enzymatic synthesis of geranyl acetate using a full factorial Design of Experiment with central point.

- study of time at which steady-state conversion was achieved for short and long PBR.

- study of catalytic stability in the PBR over a long reaction time or several repeated runs with depressurization-repressurization.

- study of the impact of $\mathrm{CO}_{2}$ flow-rate (i.e. residence time) in the PBR on the conversion $\%$ at $55{ }^{\circ} \mathrm{C}-200$ bar and $65^{\circ} \mathrm{C}-150$ bar

/

Data is with this article

Enzymatic synthesis of geranyl acetate in packed bed reactor in supercritical carbon dioxide under various pressure-temperature conditions and reactor configurations "in press."

\section{Value of the data}

- These data describe, for the first time, the combined effect of pressure and temperature variations of supercritical $\mathrm{CO}_{2}$ on Candida antarctica lipase B (CALB) catalytic properties.

- These data show how important is the appropriate control of $\mathrm{CO}_{2}$ flow-rate (i.e. reaction mixture residence time) for the achievement of a very high conversion \% together with a good process productivity.

- These data may be considered with interest by any immobilized enzyme suppliers as well as manufacturers interested in continuous, green and enzymatic synthesis of terpenes esters.

\section{Data}

The collection of the experimental data in this paper aimed to contribute to the promotion of supercritical $\mathrm{CO}_{2}$ as a green, cheap, safe solvent for the synthesis of geranyl acetate, a widely used terpene ester. In this data in brief article, we found appropriate to focus on data related to the design of experiments on the influence of pressure and temperature on the conversion \% of geraniol to geranyl acetate. We then present data related to the study of the impact of the supercritical $\mathrm{CO}_{2}$ residence time in the packed bed reactor (PBR) on the conversion \%. Finally we give supplementary data helping the reader to easily get the densities, flow rates and residence times of various supercritical $\mathrm{CO}_{2}$ produced from a $-8^{\circ} \mathrm{C}$ liquid $\mathrm{CO}_{2}$ pumped at various flow-rates. This last point is also important since when $\mathrm{CO}_{2}$ expand when passing from the liquid state to the supercritical state, its density, flow-rates but also the substrates concentrations in it, change. 


\section{Experimental design, materials, and methods}

\subsection{Design of Experiments (DoE)}

Table 1 below presents the pressure-temperature conditions used in our design of experiment as well as the corresponding conversion \% of geraniol to geranyl acetate.

Pressure was in the range $150-300$ bars with a central point at 225 bar. Temperature was in the range $45-65^{\circ} \mathrm{C}$ with a central point at $55^{\circ} \mathrm{C}$ ( - and + indicate the low and high level, respectively, for each factor. 0 indicate a central level for each factor). For each P-T conditions, a flow rate of $3 \mathrm{~mL} \mathrm{~min}{ }^{-1}$ of liquid $\mathrm{CO}_{2}$ at $-8{ }^{\circ} \mathrm{C}$ was pumped, converted to supercritical $\mathrm{CO}_{2}$ at the target pressure and temperature, and mixed with of an equimolar mixture of acetic acid and geraniol pumped at flow rate of $40 \mu \mathrm{L} \mathrm{min}^{-1}$ prior to pass through a $1 \mathrm{~mL}$ PBR filled with $300 \mathrm{mg}$ of lipozyme ${ }^{\circledR} 435$ equilibrated at a water activity of 0.23 (water activity measurement performed with a Novasina Lab-Master aw meter). The substrates concentration in $\mathrm{CO}_{2}$ was therefore $57 \mathrm{mM}$, based on the $\mathrm{CO}_{2}$ flow in a liquid form (i.e. prior to density changes when increasing pressure and temperature). Unreacted substrates as well as products geranyl acetate (no visible water traces), were collected in a liquid form by $\mathrm{CO}_{2}$ depressurization through a back-pressure regulator-separator and a $\mathrm{CO}_{2}$ flow-breaker. Collecting vials were $60 \mathrm{~mL}$ amber vials. The run time was $30 \mathrm{~min}$.

After each run, the collected volume was measured and $200 \mu \mathrm{L}$ of this volume was added to $800 \mu \mathrm{L}$ of acetone prior addition of $50 \mu \mathrm{L}$ of methyl decanoate as an internal standard. After mixing, $1 \mu \mathrm{L}$ of the sample was injected with a split ratio of 100:1 in a Agilent 7890 A gas chromatograph equipped with a Agilent HP-INNOWax $30 \mathrm{~m} \times 0.32 \mathrm{~mm}$ internal diameter $\mathrm{x} 0.25 \mu \mathrm{m}$ column and a FID detector for quantification. The GC-FID was also coupled with an Agilent $7000 \mathrm{~A}$ MS triple quad detector (Agilent technologies, Santa Clara, USA). Details are given in the article. The detection and quantification limits (LOD and LOQ) were determined for all standards according to a US-EPA method [1]. LOD and LOQ were calculated as $\left[3 \times s_{a 0} / a\right]$ and $\left[10 \times s_{a 0} / a\right]$ respectively, with $s_{a 0}$ and $a$, the standard deviation on the intercept and the slope of the calibration curve, respectively.

The conversion \% was calculated according to equation 1 as the ratio between the amount of geranyl acetate produced (mole) and the amount of geraniol (mole) pumped during the run:

$$
\text { conversion } \%=\frac{\text { amount }(\text { mole }) \text { of } \backslash \text { gerany } \backslash \text { acetate } \backslash \text { produced in } 30 \text { min run }}{\text { amount (mole) of } \backslash \text { geraniol } \backslash \text { pumped } \backslash \text { in } 30 \mathrm{~min} \text { run }} \times 100
$$

Table 1

Pressure and temperature conditions of the design of experiment.

\begin{tabular}{llll}
\hline code & Pressure (bar) & Temperature $\left({ }^{\circ} \mathbf{C}\right)$ & Conversion \% \\
\hline-- & 150 & 45 & 27,24 \\
-- & 150 & 45 & 29,88 \\
-- & 150 & 45 & 32,73 \\
-+ & 150 & 65 & 74,84 \\
-+ & 65 & 73,23 \\
-+ & 150 & 65 & 73,18 \\
0 & 150 & 55 & 42,93 \\
0 & 225 & 55 & 45,05 \\
0 & 225 & 55 & 46,21 \\
0 & 225 & 55 & 44,43 \\
0 & 225 & 55 & 44,01 \\
0 & 225 & 55 & 47,61 \\
+- & 45 & 26,51 \\
+- & 225 & 45 & 28,06 \\
+- & 300 & 45 & 29,28 \\
++ & 300 & 65 & 58,58 \\
++ & 300 & 65 & 57,93 \\
\hline
\end{tabular}


a

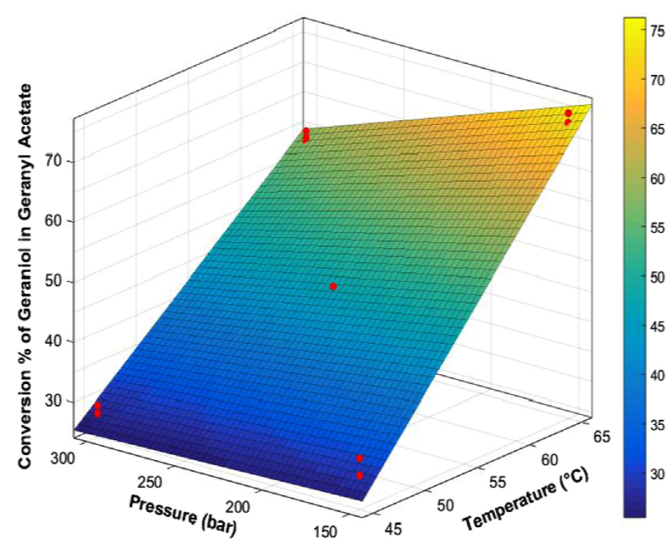

b

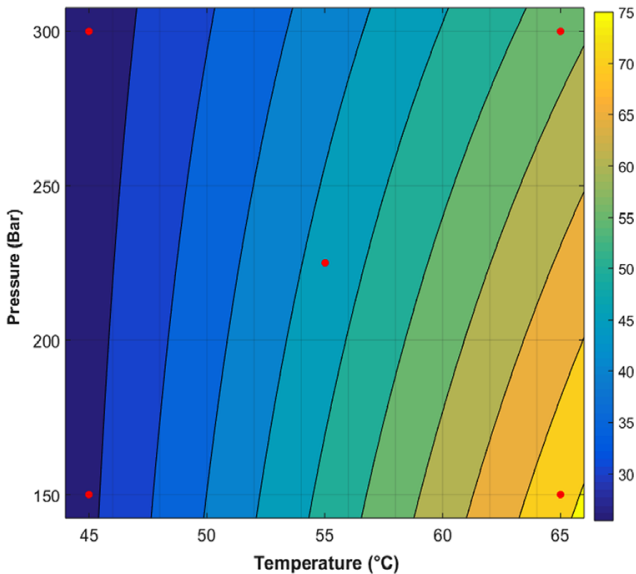

Fig. 4. Surface response (a) and isoresponse curves (b) of geraniol conversion rate to geranyl acetate versus temperature and pressure of supercritical $\mathrm{CO}_{2}$ (similar conditions with Figure 3). Red dot are experimental points ( 3 at each corner and 6 in the central position).

\section{Table 2}

Detailed data for $\mathrm{CO}_{2}$ flow rates, liquid and supercritical, residence time of supercritical $\mathrm{CO}_{2}$ in the $\mathrm{PBR}$, and corresponding conversion \% with their associated standard deviation. Experimental conditions: liquid $\mathrm{CO}_{2}$ pumped at $-8{ }^{\circ} \mathrm{C}$ and 60 bar and converted to supercritical $\mathrm{CO}_{2}$ at $55{ }^{\circ} \mathrm{C}$ and 200 bar. Use of one single $1 \mathrm{~mL}$ PBR or of two $1 \mathrm{~mL}$ PBR in parallel. PBR were filled with $300 \mathrm{mg}$ of Lipozyme ${ }^{\mathbb{R}} 435$ beads equilibrated at aw $=0.23$. Runs were performed in triplicate.

\begin{tabular}{|c|c|c|c|c|c|}
\hline nb PBR & $\begin{array}{l}\text { liquid } \mathrm{CO}_{2} \text { flow } \\
\left(\mathrm{mL} \mathrm{min}^{-1}\right)\end{array}$ & $\begin{array}{l}\text { supercritical } \mathrm{CO}_{2} \text { flow } \\
\left(\mathrm{mL} \min ^{-1}\right)\end{array}$ & $\begin{array}{l}\text { Residence time of supercritical } \\
\mathrm{CO}_{2} \text { in PBR (seconds) }\end{array}$ & Conv. \% & stdev conv \% \\
\hline 1 & 0.5 & 0.66 & 36.5 & 83 & 4 \\
\hline 1 & 1.0 & 1.31 & 18.3 & 75 & 1 \\
\hline 1 & 3.0 & 3.94 & 6.1 & 36 & 3 \\
\hline 1 & 4.0 & 5.26 & 4.6 & 27 & 1 \\
\hline 1 & 6.0 & 7.89 & 3.0 & 16 & 0 \\
\hline 2 & 1 & 0.66 & 36.5 & 83 & 4 \\
\hline 2 & 3 & 1.97 & 12.2 & 64 & 8 \\
\hline 2 & 4 & 2.63 & 9.1 & 52 & 2 \\
\hline 2 & 6 & 3.94 & 6.1 & 36 & 3 \\
\hline
\end{tabular}

Table 3

similar data as compared to Table 2 but using supercritical $\mathrm{CO}_{2}$ at $65^{\circ} \mathrm{C}$ and 150 bar and one $1 \mathrm{~mL}$ PBR. This point was added to Fig. 8 of the article.

\begin{tabular}{|c|c|c|c|c|c|}
\hline nb PBR & $\begin{array}{l}\text { liquid } \mathrm{CO}_{2} \text { flow } \\
\left(\mathrm{mL} \mathrm{min}^{-1}\right)\end{array}$ & $\begin{array}{l}\text { supercritical } \mathrm{CO}_{2} \text { flow } \\
\left(\mathrm{mL} \mathrm{min}^{-1}\right)\end{array}$ & $\begin{array}{l}\text { Residence time of supercritical } \\
\mathrm{CO}_{2} \text { in PBR (seconds) }\end{array}$ & Conv. \% & stdev conv \% \\
\hline 1 & 0.5 & 0.88 & 27.3 & 98 & 2 \\
\hline
\end{tabular}

The four corner points conditions of the DoE were tested three times whereas the central point condition was tested six times, according to JMP 10 software from SAS institute Inc. (Cary, NC, USA) recommendations [2]. Fitting of these experimental data, in a coded form, could be achieved with JMP 10 based on a simple linear model with interaction between Pressure and Temperature (results can be seen in Table 1 of the article). 


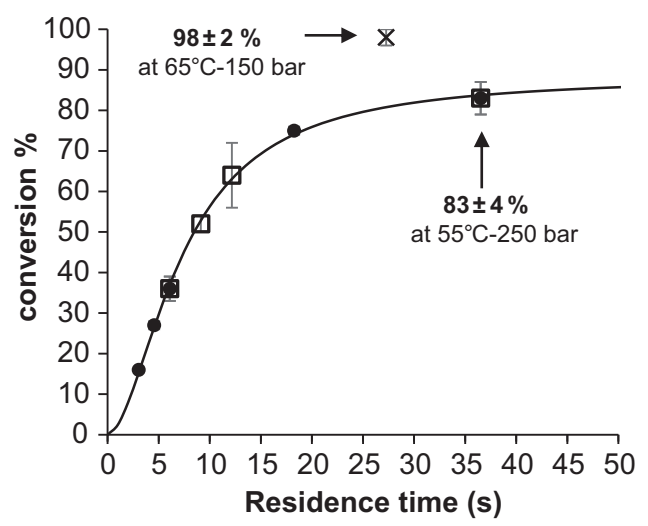

Fig. 8. Influence of supercritical $\mathrm{CO}_{2}$ residence time (i.e. of $\mathrm{scCO}_{2}$ flow-rate) on the conversion rate of geraniol to geranyl acetate. Here, changes in $\mathrm{CO}_{2}$ density when passing from liquid state to supercritical state have been used to calculate the real flow rates and corresponding residence times of supercritical $\mathrm{CO}_{2}$, as explained in supplementary material. ( $\bullet$ ) represent runs carried-out in one single short PBR containing $300 \mathrm{mg}$ Lipozyme ${ }^{\mathbb{R}} 435$ beads, ( $\square$ ) represent runs carried-out in two short PBR in parallel (i.e. using $2 \times 300=600 \mathrm{mg}$ Lipozyme ${ }^{\mathbb{R}} 435$ beads). Experimental conditions: supercritical $\mathrm{CO}_{2}$ at $55^{\circ} \mathrm{C}$ and 200 bar. Geraniol and acetic acid concentrations were kept to $57 \mathrm{mM}$ based on the liquid $\mathrm{CO}_{2}$ pumped. Additional $\mathrm{x}$ marker represents runs carried-out in one single PBR containing $300 \mathrm{mg}$ Lipozyme ${ }^{\circledR} 435$ beads with a supercritical $\mathrm{CO}_{2}$ at $65{ }^{\circ} \mathrm{C}$ and 150 bar at $27 \mathrm{~s}$ residence time $\left(0.5 \mathrm{~mL} / \mathrm{min}\right.$ liquid $\left.\mathrm{CO}_{2}\right)$ with $57 \mathrm{mM}$ of each substrates too, based on the liquid $\mathrm{CO}_{2}$ pumped. Runs were performed in triplicates.

In order to generate the surface response and isocontour plots corresponding to Fig. 4a and b of the article, respectively, we needed the coefficient of the model in a non-coded form. To do so we used the curve-fitting tool of Matlab (Mathworks, Natick, USA) and a non-linear regression based on the Levenberg-Marquardt algorithm (coefficients of the surface response equation can be seen in equation 2 of the article).

2.2. Study of the impact of supercritical $\mathrm{CO}_{2}$ (i.e. substrates) residence time in the PBR on the conversion \% of geraniol to geranyl acetate

In our Design of experiment and stability tests, we used $3 \mathrm{~mL} / \mathrm{min}$ of liquid $\mathrm{CO}_{2}$ pumped at 60 bar and $-8{ }^{\circ} \mathrm{C}$ with a density of 0.991 . All along the article, for convenience, we used the liquid $\mathrm{CO}_{2}$ flowrate as a constant basis for substrates concentration, residence times and enzymatic conversion comparisons. But it is obvious that, when passing from liquid to supercritical, $\mathrm{CO}_{2}$ density, and therefore $\mathrm{CO}_{2}$ flow-rate and substrate concentrations in the supercritical $\mathrm{CO}_{2}$, change. We used densities of supercritical $\mathrm{CO}_{2}$ as found with the Span and Wagner Equation of State defined in 1996. A free computational tool from the Energy Institute of the University of Pennsylvania was used to calculate the densities with this equation [3]. At $55^{\circ} \mathrm{C}$ and $200 \mathrm{bar}$, the density of supercritical $\mathrm{CO}_{2}$ was $754 \mathrm{~kg} \mathrm{~m}^{-3}$. At $65^{\circ} \mathrm{C}$ and $150 \mathrm{bar}$, this density was $0.559 \mathrm{~kg} \mathrm{~m}^{-3}$.

Tables 2 and 3 below shows flow-rates for liquid and supercritical $\mathrm{CO}_{2}$ as well as the residence time of supercritical $\mathrm{CO}_{2}$ in the PBR, expressed in seconds, assuming that spaces between beads is about $40 \%$ as currently considered with spherical catalyst particles. Conversion $\%$ and corresponding standard deviations were calculated with $n=3$. These data were used to generate the Fig. 8 of the article on the impact of residence time of supercritical CO2 (and therefore reaction mixture) on the conversion \%.

Table 2 lists the liquid $\mathrm{CO}_{2}$ flow-rates (at $-8{ }^{\circ} \mathrm{C}$ and 60 bar) used in experiments with one single short $1 \mathrm{~mL}$ PBR filled with $300 \mathrm{mg}$ of Lipozyme ${ }^{\circledR} 435$ beads or with two short $1 \mathrm{~mL}$ PBR in parallel, also filled with $300 \mathrm{mg}$ of Lipozyme ${ }^{\circledR} 435$ beads ( $300 \mathrm{mg} / \mathrm{PBR}$ ). The third column shows the corresponding flow-rates once that the $\mathrm{CO}_{2}$ expanded when reaching the supercritical zone at $55^{\circ} \mathrm{C}$ and 200 bar. These flow-rates are logically higher due to lower $\mathrm{CO}_{2}$ density. The fourth column gives the residence time of supercritical $\mathrm{CO}_{2}$ in the PBR (expressed in seconds). 
Table 3 lists similar data as compared to Table 2 but using supercritical $\mathrm{CO}_{2}$ at $65{ }^{\circ} \mathrm{C}$ and $150 \mathrm{bar}$, the best experimental temperature and pressure found based on our Design of Experiment.

\section{Acknowledgments}

This work was partially supported by the ANR (French National Agency for Research) through the project ISEAPIM3 (ANR-15-CE07-0023). We thank Ramiro Martinez (Novozymes Espana, S.A.) for the gift of Lipozyme ${ }^{\circledR} 435$. We also thank Jeremy Lagrue (SFE Process) for his support in designing the $\mathrm{CO}_{2}$ flow breaker used in this study.

\section{Transparency document. Supporting information}

Transparency data associated with this article can be found in the online version at http://dx.doi. org/10.1016/j.dib.2018.07.010.

\section{References}

[1] A. Hubaux, G. Vos, Decision and detection limits for linear calibration curves, Anal. Chem. 42 (1970) 849.

[2] SAS Institute Inc, Full Factorial Designs, in: JMP 10 Design of Experiments Guide, SAS Institute Inc, Cary, NC, 2012, pp. 157-166.

[3] $\mathrm{CO}_{2}$ calculator, a web computational tool, Energy Institute of the Pennsylvania State University, 〈http://www.energy.psu. edu/tools/CO2-EOS $\rangle$. 